УДК 811.111+659.13/.17

ББК 81.2-5АнгЛ

DOI: https://doi.org/10.17308/lic.2021.3/3586

\title{
ПОЛИКОДОВЫЕ ИНСТРУМЕНТЫ ПОЗИЦИОНИРОВАНИЯ БРИТАНСКИХ УНИВЕРСИТЕТОВ В РАМКАХ ЭЛЕКТРОННОЙ ИНТЕРНАЦИОНАЛИЗАЦИИ ОБРАЗОВАНИЯ
}

\author{
Е. Ю. Дьякова
}

Воронежский государственный университет

\section{POLYCODE POSITIONING TOOLS OF BRITISH UNIVERSITIES WITHIN THE ELECTRONIC INTERNATIONALIZATION OF HIGHER EDUCATION}

\author{
E. Yu. Dyakova \\ Voronezh State University
}

\begin{abstract}
Аннотация: в работе обсуждаются особенности использования инструментов позиционирования с иеелью создания позитивного имиджа британского университета. Электронная интернационализация высшего образования включает в себя создание циифрового бренда вузов с ичелью продвижения своих образовательных услуг. Цифровой бренд университета подразумевает устойчиво сформированное в сознании заинтересованных групп представление о различных аспектах деятельности университета, его научной и образовательной корпоративной культуре. Для реализации маркетинговой политики на своих веб-сайтах университеты используют средства различной семиотической природы, при этом лингвистические и паралингвистические средства, которые они используют, представляют собой не только способы передачи информации, но и оказывают определенное воздействие на целевые аудитории. В фокусе статьи находится изучение рекламного дискурса сферы высшего образования, а именно того, как различные поликодовые средства способствуют созданию цифрового бренда университета. Автор выявляет и описывает наиболее востребованные на сайтах британских университетов инструменты позииионирования, среди которых позиционирование через географическое местоположение, образовательнье программы, достижения, научный и экспертный потенциал, работодателей, выдающихся выпускников, позиционирование вуза в качестве работодателя, позиционирование через стратегию интернационализации. Все эти инструменты используются в качестве средств привлечения целевых аудиторий в университеты Великобритании и превращаются в своего рода брендинговые стратегии.

Ключевые слова: электронная интернационализаџия высшего образования, инструменты позиционирования, ијифровой бренд университета, имидж университета, поликодовый текст, рекламная стратегия.
\end{abstract}

\begin{abstract}
: the paper discusses the features of using positioning tools in order to create a positive image of a British university. Electronic internationalisation of higher education includes the creation of a digital brand of universities in order to promote their educational services. The digital brand of the university implies a concept of various aspects of the university's activities, its research and educational corporate culture, which is steadily formed in the minds of interested groups. To implement marketing policies on their websites, universities use means of a different semiotic nature, while the linguistic and paralinguistic means they use are not only ways of conveying information, but also have a certain impact on target audiences. The article focuses on the study of advertising discourse in the field of higher education, namely, how various polycode tools contribute to the creation of a digital university brand. The author identifies and describes the most popular positioning tools on the websites of British universities, including positioning through geographic location, educational programmes, achievements, research and expertise, employers, outstanding graduates, positioning a university as an employer, positioning through its internationalisation strategy. All of these tools are used as a means of attracting target audiences to UK universities and are transformed into a kind of branding strategy.

Key words: electronic internationalisation of higher education, positioning tools, digital university brand, university image, polycode text, advertising strategy.
\end{abstract}

(С) Дьякова Е. Ю., 2021

Контент доступен под лицензией Creative Commons Attribution 4.0 License.

The content is available under Creative Commons Attribution 4.0 License. 


\section{Введение}

Всеобщая компьютеризация и информатизация различных сфер жизни общества в последние десятилетия вызвали необходимость формирования новой политики в области высшего образования, в результате чего данная сфера сделала стремительный шаг вперед навстречу цифровому будущему, адаптировав современные технологии к процессу обучения и внедрив формы дистанционного и электронного взаимодействия не только в образовательный процесс и повседневную жизнь студентов и преподавателей, но и в свои маркетинговые кампании, направленные на различные целевые аудитории. Таким образом, новые реалии, вызовы времени, потребности общества, а также новые особенности взаимодействия стран породили новые тенденции в высшем образовании, важнейшими из которых стали процессы либерализации, глобализации и интернационализации. В связи с этим появилась необходимость в привлечении иностранных студентов через глобальную сеть Интернет и в создании цифровых механизмов реализации образовательного маркетинга, возникла потребность во внедрении такого нового направления политики интернационализации образовательной сферы, как электронная интернационализация высшего образования.

Электронная интернационализация высшего образования подразумевает создание цифрового бренда вузов с целью продвижения своих образовательных услуг. Для реализации маркетинговой политики на своих интернет-ресурсах университеты используют средства различной семиотической природы, а лингвистические и паралингвистические средства, которые они используют, представляют собой не только способы передачи информации, но и оказывают определенное воздействие на адресата. Высшее образование превратилось в глобальную индустрию, которая, ориентируясь на своего потребителя, участвует в гонке за талантливыми студентами и хорошей репутацией.

В фокусе данной статьи находится изучение рекламного дискурса сферы высшего образования, а именно того, как различные поликодовые средства используются британскими университетами с целью создания своего позитивного имиджа. Выявление, систематизация и описание инструментов позиционирования британских университетов на рынке образовательных услуг, а также изучение поликодовых средств их реализации на официальных сайтах рассматриваемых вузов представляет большой исследовательский интерес. Значительное место в данной статье отводится лингвистическому осмыслению стратегий позиционирования. Целью данной работы является выявление и описание наиболее популярных рекламных инструментов, используемых на официальных сайтах британских вузов.
Выбор стратегии интернационализации зависит от многих факторов. Прежде всего, страны должны руководствоваться внутренними возможностями, приоритетами, ресурсами, национальным историческим и социально-экономическим контекстом. Внешние геополитические факторы также играют роль при выборе подхода, но в меньшей мере. Все большее количество стран рассматривают интернационализацию высшего образования как предмет и объект политики комплексного развития государства для решения конкретных политических, экономических, финансовых и социальных задач.

Анализ уже имеющихся стратегий, инструментов и опыта стран, преуспевающих в ведении политики интернационализации, может быть полезен другим странам при разработке своих механизмов реализации подходов интернационализации. Интересно в данной связи проследить, как британский опыт может послужить своего рода эталоном для внедрения и развития процесса электронной интернационализации в нашей стране.

\section{Материалы и методы исследования}

В качестве источников эмпирического материала для данного исследования были взяты официальные веб-сайты десяти ведущих университетов Великобритании: Оксфордский университет, Кембриджский университет, Имперский колледж Лондона, Эдинбургский университет, Манчестерский университет, Королевский колледж Лондона, Бристольский университет, Лондонская школа экономики и политических наук, Уорикский университет, Университетский колледж Лондона. Британские вузы были выбраны для данного исследования не случайно. Согласно статистическим данным международной организации UniPage, на сегодняшний день Великобритания занимает 2-е место в мире по количеству обучающихся иностранных студентов, уступая лишь США [1].

Такому интересу к университетам Соединенного Королевства со стороны иностранных абитуриентов послужила популяризация британской академической модели высшего образования на международной арене, чему поспособствовали следующие факторы: наличие многовековой университетской традиции, устойчивость существующей образовательной модели в сочетании с осознанием необходимости модернизации образования и, как следствие, разработкой соответствующей стратегии, придание большого значения эффективному стимулированию внутренней исследовательской деятельности и развитию собственной стратегии интернационализации.

Следует подчеркнуть, что несмотря на то, что образование в вузах Великобритании и так высоко оценивается на международной арене, эта страна 
очень активно развивает собственную стратегию интернационализации. Благодаря продуманной политике собственного продвижения, британские вузы активно поддерживают свой имидж престижа, высоких ценностей, глубоких знаний и передовых исследований, о чем свидетельствует рекламный функционал университетских веб-сайтов.

В качестве методической основы исследования была взята методика анализа цифрового бренда университета, разработанная специалистами НИУ ВШЭ г. Санкт-Петербурга под руководством Российского совета по международным делам (РСМД), и освоенная нами в ходе обучения по программе повышения квалификации «Электронная интернационализация 2.0: как управлять международным digital-брендом университета» 19-23 октября 2020 г. [2]. Отобранный и систематизированный в соответствии с данной методикой материал подвергся семиотическому и лингвистическому анализу. Объектом исследования послужил поликодовый текст веб-сайтов британских университетов, а предметом - инструменты позиционирования университета и средства их реализации различной семиотической природы, используемые с целью его продвижения на рынке высшего образования.

В основе исследования лежала гипотеза о том, что использование определенных лингвистических и нелингвистических приемов позиционирования на сайтах британских университетов оказывает влияние на адресата рекламно-информационного сообщения, создает определенный положительный имидж высшего учебного заведения, в результате чего создается цифровой бренд данного вуза.

\section{Результаты исследования}

Использование университетами на своих вэб-сайтах рекламных способов продвижения позволяет говорить о таком понятии, как позиционирование. Согласно определению The Economic Times, позиционирование - это процесс формирования определенного образа товара или бренда в сознании целевой аудитории, который будет выгодно отличаться от позиций конкурентов. Позиционирование определяет положение продукта (предмета или услуги) по отношению к другим, предлагающим аналогичные продукты и услуги на рынке, а также к мнению потребителя [3]. Иными словами, позиционирование представляет собой ключевой элемент брендинга любого бизнеса. Бренд вуза, в свою очередь, представляет собой комплекс представлений, ассоциативных образов, эмоций, ценностных характеристик, которые возникают в сознании потребителя при упоминании или встрече с образовательными услугами какого-либо вуза [4]. С тех пор как система об- разования, прежде всего высшего, трансформировалась в экономический ресурс, позиционирование вузов через различные инструменты стало критически важным элементом продвижения образовательных программ, в том числе за границу. Сайт вуза в Интернете отныне является главнейшим инструментом коммуникации, передачи информации и маркетинга. Практический опыт высших учебных заведений по созданию и управлению сайтов показывает, что веб-сайт должен решать такие задачи, как поддержка имиджа вуза, маркетинг образовательных услуг, интерактивное сопровождение и улучшение образовательного процесса, установление взаимоотношений с участниками рынка, привлечение партнеров и спонсоров [5].

Перейдем теперь непосредственно к результатам нашего исследования. В ходе анализа сайтов 10 университетов Великобритании, опираясь на упомянутую выше методику исследования, нами были выявлены следующие наиболее востребованные инструменты позиционирования:

- географическое позиционирование;

- позиционирование через образовательные программы;

- позиционирование вуза через его достижения;

- позиционирование через научный и экспертный потенциал;

- позиционирование через работодателей;

- позиционирование вуза в качестве работодателя;

- позиционирование через выдающихся выпускников;

- позиционирование через стратегию интернационализации.

Объем данной статьи не позволяет детально рассмотреть особенности каждой группы средств. Кратко остановимся на каждом инструменте позиционирования и проиллюстрируем его примерами из нашей выборки.

Особенно хочется выделить первый инструмент (географическое позиционирование вуза), который был представлен на сайтах 9 из 10 рассматриваемых вузов. Так, на сайте Оксфордского университета город представлен как a beautiful city of stunning architecture, history and culture where you'll find ancient and modern colleges, fascinating museums, and parks and green spaces in which to relax; Oxford is one of the top destination in the UK. На сайте Имперского колледжа Лондона жизнь в столице Соединенного Королевства описывается следующим образом: living in London puts you at the heart of the action in the world's best student city; а сам Лондон - как best student city in the world. Эдинбургский университет так характеризует столицу Шотландии: Scotland's inspiring capital is one of Europe's great cultural hubs and a stimulating place to study. 
Обилие эпитетов (beautiful, stunning, fascinating, inspiring, great, creative, diverse, revolutionary, progressive, ground-breaking, dynamic, incredible, plentiful, colourful, offbeat, playful, playable, unrivalled) направлено на привлечение внимания пользователей сайта через красочное изображение города, его достопримечательностей, истории и инфраструктуры, которое должно появиться в сознании человека, читающего описание. Употребление олицетворений ( $a$ confident city that likes to do things differently; Bristol's character), метафор (the heart of the action; sporting pedigree; revolutionary and progressive spirit; soak up the culture; get a taste of ... through locally sourced food) еще больше насыщает текст экспрессивными красками и соответственно зарядом рекламности. Использование превосходной степени сравнения прилагательных (the world's best, the richest and most influential, most dynamic) предполагает акцентирование наивысшей степени определенного признака для привлечения внимания потребителя именно к этим моментам. С помощью всех вышеперечисленных лексических, грамматических и стилистических средств, представленных на сайтах, вузы позиционируют себя в глазах потенциальных студентов и их родителей через город с большими возможностями, в котором молодежи будет интересно жить и учиться.

Помимо вербальных средств, географическое позиционирование реализуется на сайтах с помощью таких визуальных средств, как фотографии города и университета (7 из 9 вузов), а также видео-обзор местности с высоты птичьего полета или ролик о жизни города (4 из 9 вузов).

Позиционирование вуза через образовательные программы. Поскольку одним из ключевых элементов имиджа университетов являются образовательные программы и курсы, то их конкурентоспособность играет важную роль в создании цифрового бренда вуза в целом. Привлекательность образовательных программ влияет не только на заинтересованность студентов, но и на их удержание, поэтому на сайтах всех британских вузов много внимания уделяется данному инструменту позиционирования продукта.

Анализируя описание образовательных программ и курсов рассматриваемых британских вузов, можно сделать вывод, что с помощью различных языковых средств реализуется мощный рекламный посыл для привлечения новых студентов. В обзоре направлений подготовки преобладают такие лексические и синтаксические средства экспрессивной выразительности, как эпитеты (sophisticated, distinctive, comprehensive, valuable, distinguished, remarkable, excellent, cuttingedge, exceptional, advanced, multifaceted, exciting, strong, solid, creative, inspired, unique, in-depth, rich, unrivalled, vibrant, innovation-intensive), гиперболы (unusually broad, extremely varied, hugely flexible, uniquely broad, internationally renowned, international excellence), метафоры (richness of human cultural experience; the twists and turns of literary genres; at the forefront of their fields; at the very cutting edge of the subject; set of skills), олицетворение (these courses aim to launch you), параллельные синтаксические конструкции с единоначатием (анафора) (you will benefit, you will have, you will take). Данные средства используются составителями контента для привлечения внимания целевых аудиторий, чтобы донести до них информацию о том, что обучение в данном вузе дает большие преимущества в приобретении новых знаний и навыков, незабываемый опыт и хорошие возможности трудоустройства.

Помимо языковых средств выразительности, позиционирование образовательных программ в рассмотренных университетах происходит с помощью аудиовизуальных средств: на странице каждого направления подготовки представлены небольшие видеоролики с преподавателями и студентами или выпускниками, рассказывающими о преимуществах данной программы. Также на сайтах некоторых вузов присутствуют чат-боты, наличие которых значительно повышает интерактивность сайта и позволяет университетам установить прямой контакт с потенциальным студентом. Таким образом, все вышеперечисленные способы представляют позиционирование британских вузов через свой продукт.

Позиционирование вуза через его достижения. Среди важных критериев брендинга исследователи выделяют такие, как престиж высшего учебного заведения, его репутацию, сложившийся в социуме образ вуза [6]. Позиционирование через позиции в рейтингах, участие в значимых проектах, получение грантов и победы в конкурсах также является одним из рекламных способов привлечения потенциальных студентов, который используется 7 из 10 рассмотренных британских вузов. В основном на сайтах представлена информация о позициях в национальных и мировых рейтингах, победах в конкурсах и полученных премиях.

Проведенное исследование показало, что описание достижений, позиций в рейтингах, наград и прочих заслуг университетов на их веб-страницах за счет разных языковых и визуальных средств ориентировано на создание образов сильных вузов, признанных в мировом сообществе. Такие часто встречающие существительные, как recognition, commitment, excellence, reputation, leadership, а также прилагательные top, top-quality, renowned, acknowledged, имеют положительную коннотацию и в выгодном свете представляют репутацию университета как передового вуза, признанного на мировой aрене. В тексте сайтов каждого вуза преобладают 
превосходные степени сравнения (the largest, world's best, the most sought-after, the highest, the best and bravest), создающие образ наивысшей степени общественного признания, качества проводимых исследований, предоставляемых образовательных услуг и т. п. Также можно наблюдать наличие следующих средств экспрессивной выразительности: гипербол (world-leading, internationally excellent), метафор (thought leaders of today and tomorrow), олицетворений (King's is delighted; reputation attracts and empowers), эпитетов (competitive, world-leading, excellent, research-rich, genuine, cutting-edge, renowned, brave, progressive).

Позиционирование вуза через научный и экспертный потенциал. Идеология британского подхода к позиционированию вуза в том числе исходит из его научного потенциала, так как именно научный бренд делает вуз значимым. Очевидно, что помимо прочих инструментов позиционирования большое значение в британских вузах отдается акцентированию научного потенциала, о чем свидетельствует большой массив информации о научных областях компетенций вузов. Помимо научной деятельности внутри университетов, достаточно много внимания уделяется научному сотрудничеству и партнерству с различными организациями и другими вузами. Данный инструмент позиционирования представлен у 8 из 10 британских вузов.

Проведенное исследование показывает, что научный потенциал британских вузов позиционируется по-разному, но большее внимание уделяется аудиовизуальным средствам, так как на сайте каждого вуза имеются видео-обзор научного направления с ведущим преподавателем или ученым, а также яркие изображения, формирующие у пользователя определенное представление о нем. Так, основные области и интересы научной деятельности Кембриджа представлены в разделе "Spotlights" 28 разноцветными изображениями, которые дают читателю визуальное представление о научном направлении, с небольшим фрагментом текста под каждым. Научный потенциал Имперского колледжа Лондона выражен на его сайте яркими и необычными картинками, привлекающими внимание, а также лентой научных новостей с краткими аннотациями. Позиционирование научного потенциала на сайте Уорикского университета представлено через интерактивные графические изображения его основных научных направлений, при нажатии на которые пользователь переходит на страницу с кратким описанием данного направления и одноминутным видео, в которых тезисно рассказывается об этом направлении и приводятся интересные факты.

Довольно сложно рассматривать научный потенциал вуза отдельно от его экспертного потенциала, так как они крепко взаимосвязаны: именно сильная научная база дает возможности для развития аналитики, экспертизы и прикладных исследований. На сайтах всех рассмотренных британских вузов очень подробно рассказывается о проводимых исследованиях, разработке инноваций и исследовательских проектах совместно с другими вузами и организациями. Конечно же, такие университеты, как Оксфорд и Кембридж, занимают лидирующие позиции по количеству проектов и партнеров, приносящих дополнительное финансирование.

Помимо паралингвистических средств, позиционирование осуществляется также через языковые: эпитеты (strong, competitive, pioneering, cutting-edge, renowned, dedicated, precious, embellished, significant, grand, enormous, evident, apparent, passionate, creative, supportive, excellent, successful, inspiring, outstanding, essential, extensive), метафоры (boundaries of knowledge; from fringe to frontier neuroscience; to build resilience, the heart of our planet; ideas can flourish; science happening in labs; breadth of global priorities; beacons of excellence; shape the future; catalysts for new research networks), олицетворения (neuroscience has transformed... and promises, the knowledge has the power to shape and transform our world; our partnerships help grow), метонимия (best minds together), а также существительные, имеющие положительную коннотацию (fulfilment, value, integrity, excellence, discovery, invention, innovation, achievements, humankind, understanding), которые эксплицитно доказывают значимость этих исследований и служат средством привлечения партнеров.

Позиционирование вуза через работодателей. Еще одним из факторов, повышающих имидж вуза и его репутацию, является успешное трудоустройство его выпускников. Стоит отметить, что предоставление вузами такой возможности является мощным инструментом привлечения студентов, в том числе иностранных. В связи с этим британские университеты размещают на своих сайтах информацию о перспективах трудоустройства, используя при этом различные рекламные средства. Позиционирование через работодателей представлено на сайтах 7 из 10 британских вузов.

Например, на портале Оксфордского университета в разделе трудоустройства размещен следующий слоган: great jobs for bright people. Его лаконично выраженный посыл учащимся дает понимание того, что оксфордские студенты высоко востребованы в крупных организациях. Благодаря этому создается впечатление, что обучение в Оксфорде дает хорошие перспективы для построения карьеры. Кембриджский университет активно реализует рассматриваемый инструмент позиционирования с помощью языковых средств: эпитетов (generous, enthusiastic, appreciative, 
grateful, positive, enjoyable, successful), гипербол (truly grateful, overwhelmingly positive, extremely enjoyable), метафоры (breaking down some stereotypes).

На сайтах Имперского колледжа Лондона, Эдинбургского университета, Бристольского университета и Университетского колледжа Лондона позиционирование через работодателей происходит посредством визуальной наполненности сайтов (изображений, в том числе анимационных) и четко структурированного контента. Например, у многих вузов есть разделение содержания на так называемый блокнот заметок и советов о том, как вести себя на собеседовании и какие навыки необходимо развивать для той или иной сферы деятельности, а информация о компаниях и имеющихся вакансиях представлена на других вкладках.

Позиционирование вуза в качестве работодателя. Помимо сторонних работодателей в контексте трудоустройства на сайтах британских вузов рассматривается также и трудоустройство в самом университете: студентам предоставляется возможность построить карьеру в своем alma mater. Об этом свидетельствует наличие объемной и детальной информации в разделах о трудоустройстве. При этом начать карьеру предлагается еще на этапе обучения. Также отмечается, что не все вузы одновременно предоставляют возможность трудоустройства как в своих стенах, так и в других компаниях. Позиционирование в качестве работодателя для своих студентов и сторонних исследователей реализуется в 7 из 10 британских вузов. Таким образом, мы можем сделать вывод, что среди британских вузов большое значению уделяется данному инструменту позиционирования. Продвижение рабочих мест на сайтах британских вузов происходит за счет разных художественных средств. Например, мы можем видеть такие лексические стилистические средства, как метафоры (challenge convention; deliver impact; life of our university; break boundaries; champion innovation) и эпитеты (effective, leading, welcoming, wholeheartedly, thriving, creative, world-leading, outward-looking, crucial, dedicated, competitivee, excellent, inclusive, diverse, supportive, rewarding, generous, productive, enjoyable); такую стилистическую фигуру, как анафора (research, recruitment, retention, reward, recognition). Частотность употребления императивов (get a job; join community; develop your career; join us) и других глаголов (support, enhance, promote, excel, engage), носящих побудительный характер, осуществляет призыв к определенному действию - работать в вузе. Также обилие существительных с положительной коннотацией (achievement, excellence, well-being, development, equality, diversity, inclusion, satisfaction, ambition, desire, progress, curiosity, aspiration, success, support, opportunities, premium, reward, betterment) служит мощным инструментом привлечения внимания пользователя сайта. Стоит особо отметить сайт Бристольского университета, на котором довольно большое внимание уделяется своему позиционированию в качестве работодателя, так как ко всем перечисленным возможностям прилагается более детальное описание с красочными изображениями.

Позиционирование вуза через выдающихся выпускников. Выдающиеся выпускники - это гордость университета. Известные личности создают авторитетный имидж для своего вуза. Некоторые вузы ассоциируются с целыми плеядами выдающихся людей. Именно поэтому вузы часто рекламируют себя через известных выпускников и широко используют этот маркетинговый инструмент на своих страницах в Интернете. Позиционирование через выдающихся выпускников представлено у 8 из 10 рассмотренных британских вузов.

У выпускников Оксфордского университета даже есть свое название - Oxonians, которое при переводе на русский язык теряет свою уникальность. В разделе “Famous Oxonians" на сайте Оксфорда представлен коллаж с самыми выдающимися выпускниками и список имен, дифференцированный по векам. На общем коллаже знаменитые студенты нашего времени изображены в цветной палитре, а выдающиеся личности прошлых веков иллюстрированы в черном-белом цвете. При этом на сайте о них написано кратко и лаконично: gifted men and women.

На веб-странице Кембриджского университета большое внимание уделяется обладателям Нобелевской премии, окончившим Кембридж. Их заслуги охарактеризованы следующим образом: significant advances, discovery of..., development of ..., the mastery of... На сайте представлены все лауреаты премии с описанием их заслуг начиная с 1904 г. и заканчивая 2020 г. Заслуги обладателей Нобелевской премии, обучавшихся в Эдинбургском университете, тезисно описаны на сайте и распределены по категориям (физика, химия, физиология и медицина и др.), которые коррелируют с основными направлениями научной деятельности вуза.

Королевский колледж Лондона предлагает пользователю начать знакомство с его выдающимися выпускниками с просмотра 3-минутного ролика. На заставке видео жирным шрифтом написано it's our deeds that define us, а над ним красуется надпись: since its founding, King's has educated some of the world's foremost thinkers, leaders and innovators, and welcomed exceptional academics; we have a history of making advances that have shaped modern life; creative writers nurtured at King's. Под видео представлен список Нобелевских лауреатов и описание их заслуг. На сайте Бристольского университета тоже представлен исчерпывающий перечень Нобелевских лауреатов 
вуза. Университет подчеркивает, что the academic quality of the University is reflected partly in the Nobel Prizes.

В разделе выдающихся выпускников Лондонской школы экономики и политических наук представлен исторический блог, в котором рассказывают об обладателях Нобелевской премии и других значимых личностях, вышедших из дверей Лондонской школы экономики и политических наук.

Итак, мы видим, что позиционирование британских вузов через выдающихся личностей происходит в основном за счет визуальных средств (изображения и видео) и языковых (эпитетов). Gifted, significant, epic, distinguished, significant, foremost, exceptional, creative, inspirational - все эти прилагательные описывают сильных, образцовых, одаренных личностей, в которых превращаются студенты рассмотренных университетов за время обучения. Метафоры (shaped modern life; writers nurtured at King 's), которые встречаются на сайте Королевского колледжа Лондона, придают учебе в данном вузе дополнительную престижность. Такие существительные, как advances, development, discovery, mastery, expertise, deeds, имеют сильный рекламный заряд, направленный на привлечение потенциальных студентов.

Позиционирование вуза через стратегию интернационализации. Последним и немаловажным инструментом позиционирования вуза является продвижение его стратегии интернационализации. На большинстве сайтов (у 8 из 10 рассмотренных вузов) представлена стратегия интернационализации, в которой сформулированы цели в области институциональных партнерств, исследовательского сотрудничества и широкий перечень конечных показателей по набору иностранных учащихся на предстоящие годы. Эта стратегия часто включает шаги по интернационализации учебных планов, увеличению разнообразия университетской общественной жизни и подготовке выпускников как «граждан мира». Также на многих сайтах анализируемых британских вузов позиционируется транснациональное образование. Оно подразумевает совместное обучение, которое начинается в другой стране, а завершается в Великобритании.

Приведем несколько ярких примеров. Позиционируя себя через стратегию интернационализации, Королевский колледж Лондона указывает на сайте, что we are an international community that serves the world. Основное видение вуза в реализации стратегии интернационализации сформулировано следующим образом: at the heart of our vision for internationalisation are... the ability to see the world through the lens of others, cultural competency at home, abroad and online; building a better, fairer world with the best minds. Также на сайте представлено 5-минутное видео, в котором более подробно рассказывается о стратегии интернационализации Королевского колледжа, включая сведения о его целях и ценностях.

Кембриджский университет определяет свою международную деятельность как international activities in pursuit of its mission to contribute to society through excellence of education, learning and research. В рамках стратегии интернационализации реализуются разные проекты университета, дифференцированные по географическому признаку. Например, в проекте, направленном на взаимодействие с Африкой, указано, что Кембридж предлагает vibrant teaching and research programmes для африканских университетов. В проекте по сотрудничеству с Европой говорится, что through high-level participation... Cambridge is committed to active and positive engagement with its partners.

Помимо средств выразительности языка, в качестве драйверов позиционирования стратегии интернационализации на сайтах британских вузов используются также аудиовизуальные средства: картинки, видео, изменение шрифтов и выделение важной информации другим цветом.

\section{Заключение}

Учитывая положение британских вузов на международной арене и тот положительный имидж, который имеется в сознании у людей не только в Великобритании, но и во всем мире, вузы можно назвать брендом, который гарантирует качество образования и высокую конкурентоспособность.

Проведенное исследование позволяет сделать вывод о том, что британские университеты активно используют на своих веб-сайтах различные поликодовые инструменты позиционирования с целью создания своего электронного бренда.

Следует отметить, что интернет-ресурсы данных высших учебных заведений активно использовали большинство инструментов позиционирования, выделенных для анализа. Анализ способов рекламного продвижения британских вузов был проведен по следующим критериям: географическое позиционирование, позиционирование через образовательные программы, позиционирование через достижения, позиционирование через научный и экспертный потенциал, позиционирование через работодателей, позиционирование вуза в качестве работодателя, позиционирование через выдающихся выпускников, позиционирование через стратегию интернационализации. Проведенный анализ показал, что в большинстве университетов позиционирование осуществляется через эти 8 инструментов. Данный факт позволяет судить о полноценной рекламной укомплектованности британских сайтов. 
Если рассматривать сайты британских вузов с точки зрения дизайна, навигации и интерактивности, то и здесь проработаны все нюансы. Интерфейсы всех веб-страниц довольно удобны для посетителя: сайты хорошо структурированы, и поиск нужной информации не занимает много времени. Несмотря на большой объем предоставленной информации, веб-сайты британских университетов отличаются простотой и строгостью стиля с логической иерархией и группировкой контента по разделам. Интерактивный функционал сайта, в том числе его коммуникационные возможности, представлен через наличие обратной связи, ссылок на социальные сети, возможности регистрации на сайте и внутренней информационной системы, с помощью которой студенты могут оперативно взаимодействовать с преподавателями. Вследствие сочетания и разнообразия компонентов интернет-маркетинга британских университетов можно говорить об эффективности работы их веб-сайтов, что в значительной степени способствует укреплению цифрового бренда вузов.

Таким образом, британские вузы осуществляют активное продвижение собственного бренда и продукта, о чем свидетельствует исчерпывающий набор способов и инструментов привлечения внимания. Британские вузы характеризует комплексный и тщательно продуманный подход как к увеличению экспорта высшего образования, так и к его интернационализации в целом. Можно сделать вывод о том, что британское образование позиционируется уже как национальный бренд, который позволяет достигать устойчиво высоких показателей по привлечению иностранных студентов и, как следствие, вносить вклад в развитие экономики страны.

\section{ЛИТЕРАТУРА}

1. Международные студенты. UniPAge. URL: https://www.unipage.net/ru/student_statistics

2. Электронная интернационализация 2.0 : как управлять международным digital-брендом университета. URL: https://spb.hse.ru/electronic_internationalization/

3. Definition of 'Positioning. The Economic Times. URL: https://economictimes.indiatimes.com/definition/ positioning

4. Branding knowledge : Brand building beyond product and service brands // Journal of Brand Management. URL: https://www.researchgate.net/publication/233712021 Branding_knowledge_Brand_building_beyond_product_ and service brands

5. Электронная интернационализация : англоязычные интернет-ресурсы российских университетов (2020 г.) : доклад РСМД No 57/2020 / [И. Н. Тимофеев и др.] ; Российский совет по международным делам. М. : НП РСМД, 2020. 60 c. URL: https://russiancouncil.ru/ activity/publications/elektronnaya-internatsionalizatsi- ya-angloyazychnye-internet-resursy-rossiyskikh-universitetov-2020-g/

6. Александров Н. Н. Привлекательность и идентичность. URL: http://alexnn.trinitas.pro/files/2011/07/ Brend_14-a.pdf

\section{иСТОЧники}

1. URL: https://www.ox.ac.uk/

2. URL: https://www.cam.ac.uk/

3. URL: https://www.imperial.ac.uk/

4. URL: https://www.ed.ac.uk/

5. URL: https://www.manchester.ac.uk/

6. URL: www.kcl.ac.uk

7. URL: http://www.bristol.ac.uk/

8. URL: https://www.lse.ac.uk/

9. URL: https://warwick.ac.uk/

10. URL: https://www.ucl.ac.uk/

\section{REFERENCES}

1. Mezhdunarodnye studenty. UniPAge. Available at: https://www.unipage.net/ru/student_statistics

2. Elektronnaya internatsionalizatsiya 2.0: kak upravlyat' mezhdunarodnym digital-brendom universiteta. Available at: https://spb.hse.ru/electronic_internationalization/

3. Definition of 'Positioning. The Economic Times. Available at: https://economictimes.indiatimes.com/definition/positioning

4. Branding knowledge : Brand building beyond product and service brands. In: Journal of Brand Management. Available at: https://www.researchgate.net/publication/233712021_Branding_knowledge_Brand_building_beyond_product_and_service_brands

5. EHlektronnaya internatsionalizatsiya: angloyazychnye internet-resursy rossijskikh universitetov (2020 g.) : doklad RSMD No. 57/2020 / [I. N. Timofeev, E. O. Karpinskaya, D. O. YArkova, M. A. Frantsuzova, I. A. Bocharov]; Rossijskij sovet po mezhdunarodnym delam (RSMD). M.: NP RSMD, 2020. 60 p. Available at: https://russiancouncil. ru/activity/publications/elektronnaya-internatsionalizatsiya-angloyazychnye-internet-resursy-rossiyskikh-universitetov-2020-g/

6. Aleksandrov N. N. Privlekatel'nost' i identichnost'. Available at: http://alexnn.trinitas.pro/files/2011/07/ Brend_14-a.pdf

\section{SOURCES}

1. Available at: https://www.ox.ac.uk/

2. Available at: https://www.cam.ac.uk/

3. Available at: https://www.imperial.ac.uk/

4. Available at: https://www.ed.ac.uk/

5. Available at: https://www.manchester.ac.uk/

6. Available at: www.kcl.ac.uk

7. Available at: http://www.bristol.ac.uk/

8. Available at: https://www.lse.ac.uk/

9. Available at: https://warwick.ac.uk/

10. Available at: https:/www.ucl.ac.uk/ 
Воронежский государственный университет

Дьякова Е. Ю., доиент кафедры английской филологии

E-mail: elenadiakova@inbox.ru

Поступила в редакциюю 20 мая 2021 г.

Принята к публикаџии 15 июня 2021 г.

Для цитирования:

Дьякова Е. Ю. Поликодовые инструменты позиционирования британских университетов в рамках электронной интернационализации образования // Вестник Воронежского государственного университета. Серия: Лингвистика и межкультурная коммуникация. 2021. № 3 . C. 95-103. DOI: https://doi.org/10.17308/lic.2021.3/3586
Voronezh State University

Dyakova E. Yu. , Associate Professor of English Philology Department

E-mail:elenadiakova@inbox.ru

Received: 20 May 2021

Accepted: 15 June 2021

For citation:

Dyakova E. Yu. Polycode positioning tools of British Universities within the electronic internationalization of higher education. Proceedings of Voronezh State University. Series: Linguistics and Intercultural Communication. 2021. No. 3. Pp. 95-103. DOI: https://doi.org/10.17308/ lic. $2021.3 / 3586$ 